\title{
Government Supervision on Explosive Enterprises' Immoral Behaviors in E-Commerce Enterprises: An Evolutionary Game Analysis
}

\author{
Liang Shen $\mathbb{D}^{\mathrm{D}},{ }^{1}$ Yuanyuan Chen $\mathbb{D}^{\mathrm{D}},{ }^{1}$ Runjie Fan $\mathbb{D}^{\mathrm{D}},{ }^{1}$ and Yuyan Wang $\mathbb{D}^{2}$ \\ ${ }^{1}$ School of Public Finance and Taxation, Shandong University of Finance and Economics, Jinan, Shandong 250014, China \\ ${ }^{2}$ School of Management Science and Engineering, Shandong University of Finance and Economics, Jinan, \\ Shandong 250014, China
}

Correspondence should be addressed to Yuyan Wang; wangyuyan1224@126.com

Received 15 December 2020; Revised 19 January 2021; Accepted 30 May 2021; Published 10 June 2021

Academic Editor: Baogui Xin

Copyright (c) 2021 Liang Shen et al. This is an open access article distributed under the Creative Commons Attribution License, which permits unrestricted use, distribution, and reproduction in any medium, provided the original work is properly cited.

Explosive enterprises' immoral behaviors in the online shopping market are widespread and have not been effectively solved. Especially in developing countries, there is a direct relationship between massive immoral behaviors and the inefficiency of government supervision. Using an evolutionary game, this paper finds that immoral behavior is more likely to spread in online markets than in traditional markets. Only when government supervision and punishment are large enough and government's punishment for the illegal enterprise exceeds extra supervision costs that government pays, explosive immoral behaviors can be curbed. Additionally, consumer support is an essential factor in improving the efficiency of government supervision. This study sorts out the interactions between e-commerce market participants and the government, obtains a path to achieve efficient government regulation, and offers management insights. The findings can serve as a reference for ensuring order in the emerging online shopping market and can also provide theoretical references for future related research.

\section{Introduction}

With the development of the internet economy, online shopping has become a mainstream consumption method, which has increased the flexibility of shopping [1] and also reduced shopping time and shopping cost for consumers [2]. According to the 2017 World E-Commerce Report released by China International Electronic Commerce Center (CIECC), the global online retail transaction volume reached $\$ 3.5$ trillion in 2019 , accounting for $14.12 \%$ of the total global retail sales. In most developed countries, more than half of the population buys goods and services online. Among them, the growth rates of e-tailing in India, China, South Korea, and the United States were 31.9\%, 27.3\%, 18.1\%, and $14.0 \%$, respectively, and online shopping has become a globalized form of consumption (https://www.chyxx.com/ industry/202010/902336.html). In recent years, internet and digital technologies have developed rapidly in China, and the online shopping market in China is also expanding rapidly. By the end of 2019, the scale of China's e-commerce transactions and online payment transactions reached CNY 34.81 trillion and CNY 249.88 trillion, respectively (https:// www.chyxx.com/research/202009/897364.html). The scale of China's digital economy added value reached CNY 35.8 trillion, which has steadily ranked the second in the world. Some organizations predict that, with the impact of big data, cloud computing, artificial intelligence, blockchain, and other technologies on the online shopping market, online shopping will become the main shopping method in the future. The proportion of online shopping in total retail sales of consumer goods is expected to reach $20 \%-25 \%$ in 2020 .

At the same time, the economic and ethical consequences of enterprises' immoral behaviors in network markets are more serious than those in traditional markets. Most directly, the massive expansion of enterprises' immoral behaviors will reduce national tax revenue on a large scale, 
which leads to massive economic losses. For example, research by the UK's Center for Economic and Commercial Research showed that, in 2016 alone, counterfeit goods caused British to lose $£ 17.3$ billion, reducing employment opportunities by 72,000 (http://www.independent.co.uk/ money/counterfeit-goods-tempting-danger-a7473751.html). It is easy to overlook that enterprises' immoral behaviors in network markets can destroy the ethical climate of the market [3], which can create a vicious cycle. On the one hand, enterprises' immoral behaviors can elicit immoral retaliation from consumers [4]. Consumers' perceptions of corporate behavior are fundamentally rooted in morality [5], and consumers who are subjected to enterprises' immoral behaviors can have a desire for revenge and retaliation [6], thus making the online shopping environment more chaotic. On the other hand, the process of spreading immoral behavior in network markets is similar to the process of virus spreading [7]. Once the fraudulent profiteering is not punished promptly, the negative incentive will spread contagiously in the society, forming "explosive immoral behaviors (EIBs)."

EIB is a phenomenon in which economic actors act to the detriment of others while maximizing their own utility [8]. There are many causes of EIBs, such as asymmetric information between supply and demand [9], corporate ethical failures [10], excessive corporate pressure [11], ineffective government regulation [12], and consumers' desire to purchase counterfeits [13]. Among them, information asymmetry is a prerequisite for the existence of such problems. However, due to the inaccessibility of online goods and the mixed nature of product information, the asymmetry of information between merchants and consumers in online marketplaces is exacerbated, ultimately resulting in market failures $[14,15]$. This is demonstrated, on the one hand, by the fact that product quality problems have been generalized in the network market. In 2018, GAO staff in the United States conducted a study (the report can be retrieved from http://www.amz123.com/thread-48343.htm? sort $=$ desc). They secretly purchased four branded goods (Nike Air Jordan sneakers, Yeti Mug, Urban Decay cosmetics, and UL-certified mobile phone chargers) from five popular e-commerce platforms, namely, Amazon, Walmart, Sears, Newegg Network, and eBay, and the results showed that 20 of the 47 products purchased were fakes. In a survey in the UK, $75 \%$ of respondents reported that they had bought fakes (the report can be retrieved from https://k.sina. cn/article_6474654027_181eb614b00100659f.html?

http=fromhttp). A new study by Velocity $M R$, a market research firm in India, found that $30 \%$ of e-commerce products in India are fakes (the study can be retrieved from https://www.cifnews.com/article/34924). In China, according to the survey, $77.8 \%$ of e-commerce platforms have fakes on sale, and $98 \%$ of online customers have purchased fakes (the report can be retrieved from http://www.kjeport.com/ detail/article/2015_1/1_26/2038796_1.shtml). The other hand of EIBs is that ethical misconduct in the network market has expanded, including distortion of goods display information, ethical misconduct of big data marketing, and large-scale tax avoidance. For example, in 2002, Amazon was exposed to the fact that the purchase price of the same item for members would be higher than the purchase price for nonmembers (the study can be retrieved from https://www. researchgate.net/publication/262493771_When_big_data_ meets_dataveillance_The_hidden_side_of_analytics). And in 2019 , a social survey in China showed that $88.32 \%$ of the respondents believed that "overcharging familiar customers" through big data was widespread, and $56.92 \%$ of the respondents said they had been "overcharged" (the report can be retrieved from http://news.timedg.com/2019-03/28/ 20821145.shtml). As seen above, the phenomenon of EIBs in the network market is intensifying. This will make the lawabiding enterprise management behavior unsustainable, which not only seriously affects the competitive environment of the online shopping market but also provides reasons for government regulation.

In 2017, UK police have shut down 28,000 websites selling counterfeit goods, more than 4,000 of which were set up by stealing customers' identity information and using their names. In 2019, the E-Commerce Law of the People's Republic of China came into effect to maintain order in the network market. In 2020, the US signed the first Executive Order 19304 (E.O. 13904) to stop the flow of counterfeit goods and other contraband into the US marketplace. The executive order focuses on combating counterfeit goods traded on third-party online e-commerce platforms, including Alibaba, Amazon, and eBay. However, the EIBs in the network market have not been stopped. This is because the attitude of enterprises toward government supervision may be disobedience or manipulation besides compliance [16]. Especially when the target of government supervision is not a minority group in the market, the regulatory authority will face an awkward situation of lawlessness, which more easily leads to the failure of regulation and enforcement. Meanwhile, government supervision can incur substantial costs, and ineffective or inefficient regulation may even reduce social welfare. Therefore, it is crucial to find the right and efficient path of governmental supervision to mitigate and curb EIBs in the network market.

The main contributions of this paper are as follows:

(i) This study elucidates the intrinsic logical relationship among the network market characteristics, the e-commerce enterprises' behaviors, and government regulation in order to better analyze the causes of current government supervision inefficiencies

(ii) This paper analyzes the evolutionary process and internal mechanism of EIB through evolutionary games, highlights the role of government supervision in curbing EIBs in online markets, and obtains a path to achieve efficient government regulation

(iii) This paper uses the Chinese government's regulation of EIBs in online markets as an example to verify the results obtained in the evolutionary game and to provide some managerial insights for countries where EIB regulation is inefficient or even ineffective

The study is structured as follows: the literature review is presented in Section 2. Section 3 gives a dynamic game 
model for the choice of immoral strategies of large- and small-scaled enterprises to analyze the inherent relationship between enterprise behaviors and government supervision. In Section 4, the evolutionary game model is constructed, and an effective strategy for the government to regulate the network market is given. Finally, Section 5 gives conclusions and management insights.

\section{Literature Review}

The purpose of this paper is to clarify the inherent logical relationship between the characteristics of enterprise behaviors, network market characteristics, and government regulation and to explore the feasible conditions and implementation paths for government supervision of the network market. Therefore, in this section, whether EIBs in the network market require government supervision will be clarified, and the contribution and shortcomings of the literature on government supervision in the network market will be summarized.

Some scholars have focused on the managerial value of organizational ethics in response to enterprises' immoral behaviors in traditional markets $[17,18]$ and have insisted that the market is the best regulator of immoral behaviors rather than the government $[19,20]$. However, online marketplaces differ from traditional markets. Mavlanova et al. [21] pointed out that the short duration of a single transaction when shopping online makes it more difficult for consumers to identify fraud signals. Meanwhile, Bergh et al. [22] argued that online sellers lack the awareness to recognize fraud signals. As a result, EIBs in the network market are more likely to arise and more insidious [23]. Another segment of scholars has noted the privacy risks of online marketplaces. Walsh et al. [24] concluded that the current federal and state laws in the United States are unable to protect the privacy of online buyers and highlighted the role of government regulation in protecting privacy. Mutimukwe et al. [25] suggested that the perceived privacy risk of e-marketplace users reduces their purchase utility. Anic et al. [26] showed that online shoppers want less privacy disclosure and that government regulation is very weak on privacy aspects of online marketplaces.

Previous studies generally agree that the emergence of online marketplaces has exacerbated EIBs of firms and caused market failures [27]. Calkins et al. [28] argued that although market regulators have more information about fraudulent transactions than government regulators, they have no incentive to proactively check for extensive online sellers who trade counterfeit goods. González [29] similarly believed that commercial interests also prevent the implementation of market regulation. To et al. [14] and Safaei and Thoben [7] showed that immoral behaviors in online shopping markets are more likely to arise and spread as information asymmetry between merchants and consumers is further amplified, which leads to EIBs and market failures. Thus, while market regulation shows great strengths and potential in combating fraudulent transactions, it is still exposed to the general weaknesses of commercial self-regulation. Only government intervention in the network market to regulate businesses is likely to create new constraints on profit-seeking behavior and thus mitigate EIBs [30].

In the research related to government regulation in the network market, some scholars believed that the law is a key factor in regulating immoral behaviors. According to the empirical analysis on data from 30 countries, Oxley and Yeung [31] found that the law can effectively promote the healthy development of e-commerce. Martinsons [32] believed that forceful regulation and explicit law are the important conditions of e-commerce development. Examining how e-commerce law should be developed in the United States, Ribstein and Kobayashi [33] argued that the e-commerce law should be enacted by states rather than federal. The flexibility and variability of state lawmaking and competition between state legislatures can contribute to government regulation. AlGhamdi and Drew [34] pointed out that the lack of explicit regulations and ineffective government supervision are key factors affecting the immoral behaviors of e-commerce enterprises. Agrawal et al. [35] suggested that the government needs to participate in the development of e-commerce rules within the legal framework. Kim [36] noted that legal changes should be used for the maintenance of e-marketplace stability and explored how the government can regulate the use and identification of electronic signatures. Additionally, some scholars have given other suggestions for the government to regulate immoral behaviors in the network market. In terms of how to improve government supervision efficiency, Weiser [37] believed that public institutions need to cooperate with private sectors with technological advantages to improve government supervision efficiency. Marsden [38] proposed that the public institutions, private sectors, and civil society institutions should jointly participate in the supervision of the network market to form a supervision mode of collaborative management.

In summary, for immoral behaviors in the network market, the extant literature mainly discussed the importance of government supervision and its key elements from a macroperspective. Few scholars probe into the inherent logical relationship between government supervision and EIBs and explore the specific implementation of the government supervision mechanism. It is believed that the current inefficiency of government supervision is related to the lack of analysis of the evolutionary process and mechanism of e-commerce enterprises' immoral behaviors from a microperspective. Therefore, this study uses the evolutionary game as an analysis tool to uncover the inherent mechanism of e-commerce enterprises' immoral behaviors and government supervision. A stable game strategy to improve the efficiency of government supervision and corresponding implementation measures are proposed.

\section{Mechanism of Explosive Immoral Behaviors of E-Commerce Enterprises}

Compared with traditional enterprises, EIBs are more likely to occur in e-commerce enterprises due to characteristics of the network market, such as virtual transaction entities and 
the lower threshold of entry and exit. Consumers are faced with too much virtual data to make sensible choices, which makes the e-commerce enterprises' EIBs present the characteristics of universality, diversity, and difficulty to regulate.

The game process of government supervision and e-commerce enterprises is illustrated with figures. Assume that e-commerce enterprises can choose two strategies: one is to disclose true quality information of products, and this strategy is marked as $\mathrm{MO}$; the other is to provide false quality information of products, that is, the enterprise adopts the immoral behavior, and this strategy is marked as IM. Suppose there are two competitive enterprises of $E 1$ and $E 2$ in the network market, and their scales and costs are different. Assume that $E 1$ is large in scale and low in cost, and $E 2$ is large in scale and high in cost. When the degree of government supervision is $S$, the strategic choices and profits of the two enterprises are shown in Figure 1.

Obviously, when $\mathrm{MO}$ is adopted by two enterprises, the profit of $E 1$ is greater than that of $E 2$. When both enterprises choose IM, the probability of $E 1$ being discovered and penalized is greater which is illustrated by the larger slope in the profit curve of $E 1$ than E2. When adopting immoral behaviors, small- and medium-sized enterprises (SMEs) are more difficult to supervise. As can be seen from Figure 1, SMEs will give up fakes only when $S>S^{* *}$.

As can be seen from Figure 1, when the degree of government supervision is small $\left(0<S<S^{*}\right)$, two enterprises will choose IM, and the profit of $E 1$ is greater than that of $E 2$; as $S$ increases, the profits of both enterprises adopting IM will decrease, and the profit of $E 1$ decreases more. When $S \in\left(S^{*}, S^{* *}\right)$, it is more advantageous for $E 1$ to choose MO, while $E 2$ still adopts IM. When $S>S^{* *}$, two enterprises will choose $\mathrm{MO}$, and when the degree of government supervision is large enough $\left(S>S^{\prime \prime}\right), E 1$ with IM is more severely penalized, and its profit will be smaller than E2 with IM.

In order to further explain the government supervision strategy, a more detailed discussion is given to connect the government supervision and the immoral costs of different enterprises. It is assumed that there are e-commerce enterprise $L 1$ and e-commerce enterprise $L 2$ with different scales and costs. Enterprise $L 1$ is small in scale and high in cost, whose cost is $C_{L 1}$ and profit is $\Delta \pi_{L 1}$ when adopting IM. Enterprise $L 2$ is large in scale and low in cost, whose cost is $C_{L 2}$ and profit is $\Delta \pi_{L 2}$ when adopting IM. It is assumed that $\Delta \pi_{L 2}>\Delta \pi_{L 1}$ and $C_{L 2}<C_{L 1}$, and the degree of government supervision is $S$. The relationship among $S$, the profits, and the costs when enterprises adopt IM is shown in Figure 2.

When the cost and the profits of enterprises adopting IM are located in region $\mathrm{I}$, there is $C_{L 1}>\Delta \pi_{L 1}$ and $C_{L 2}>\Delta \pi_{L 2}$. This means that the enterprise is not profitable when adopting IM. Even if the government does not supervise, the enterprises will not adopt IM. Region I is regarded as an invalid zone of IM.

Region II represents $C_{L 1}<\Delta \pi_{L 1}, \quad C_{L 2}>\Delta \pi_{L 2}$, and $S<\Delta \pi_{L 1}<\Delta \pi_{L 2}$. This region is the invalid zone for $L 2$ adopting IM, so $L 2$ will adopt MO. Because $S$ is weak, $L 1$ can gain profit by IM, so $L 1$ will adopt IM.

Region III represents $C_{L 1}<\Delta \pi_{L 1}, C_{L 2}<\Delta \pi_{L 2}$, and $S<\Delta \pi_{L 1}<\Delta \pi_{L 2}$. In this region, both $L 1$ and $L 2$ can gain

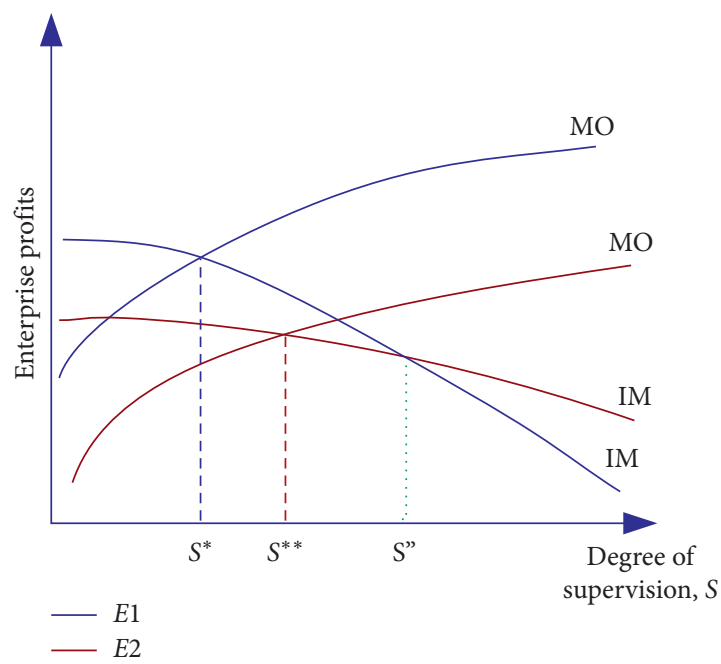

FIgURE 1: Profits of heterogeneous enterprises under government supervision.

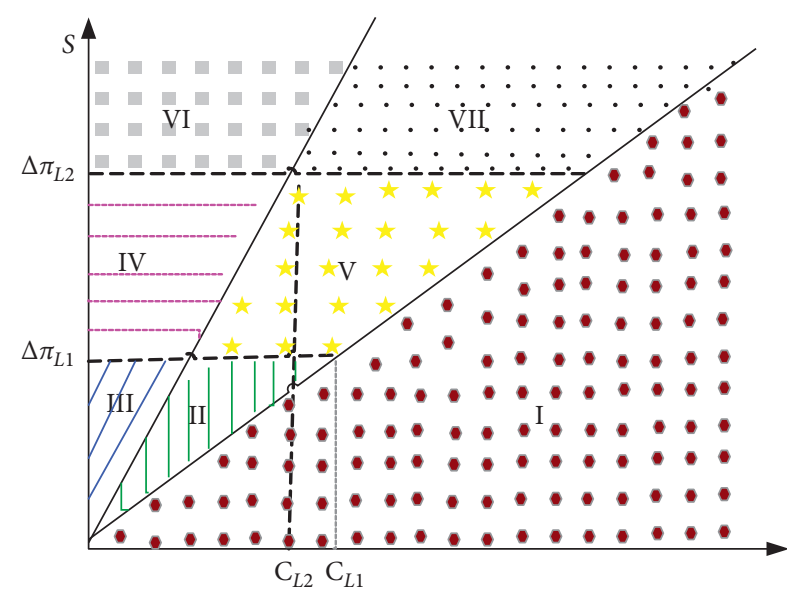

FIGURE 2: Relationship among $S$, profit, and cost under IM.

profits by IM. Because $S$ is weak, both $L 1$ and $L 2$ will adopt IM.

Region IV represents $C_{L 1}<\Delta \pi_{L 1}, C_{L 2}<\Delta \pi_{L 2}$, and $\Delta \pi_{L 1}<S<\Delta \pi_{L 2}$. In this region, both $L 1$ and $L 2$ can gain profits from IM, but $S$ is effective for enterprise $L 1$ and ineffective for enterprise $L 2$. So, $L 1$ will adopt $M O$ and $L 2$ will adopt IM.

Region V represents $C_{L 1}<\Delta \pi_{L 1}, \quad C_{L 2}>\Delta \pi_{L 2}$, and $\Delta \pi_{L 1}<S<\Delta \pi_{L 2}$. This region is the invalid region of $L 2$ adopting IM, so enterprise $L 2$ will adopt MO. Although $L 1$ can obtain profit by IM, $L 1$ still adopts MO because $S$ is strong. Therefore, this region is an effective region of government supervision.

Region VI represents $C_{L 1}<\Delta \pi_{L 1}, C_{L 2}<\Delta \pi_{L 2}$, and $\Delta \pi_{L 1}<\Delta \pi_{L 2}<S$. In this region, although both $L 1$ and $L 2$ can obtain profit by IM, $L 1$ and $L 2$ have to adopt MO due to the stronger government supervision $S$; that is, this region is also an effective region of government supervision.

Region VII represents $C_{L 1}<\Delta \pi_{L 1}, C_{L 2}>\Delta \pi_{L 2}$, and $\Delta \pi_{L 1}<\Delta \pi_{L 2}<S$. The region is the invalid region of $L 2$ adopting IM. Although $L 1$ can gain profit, government 
supervision $S$ is very strong, and both enterprises adopt MO. This region is also an effective region of government supervision.

Through the analysis of the models, it is indicated that when the competitive enterprise chooses IM, the enterprise choosing MO obtains a lower profit. When the declining speed of the enterprise's profit is slower by the increase of government supervision, the enterprise will adopt IM in a larger range $\left(0<S<S^{* *}\right)$; otherwise, the enterprise will adopt IM in a smaller range $\left(0<S<S^{*}\right)$. That is to say, the competitor's choice of IM can stimulate other enterprises to adopt IM, thus inducing the EIB. Government supervision has become an important factor affecting enterprise strategy choices.

\section{The Evolutionary Game between Government Supervision and Strategy Choices of E-Commerce Enterprises}

In practice, government supervision on e-commerce enterprises needs costs, which directly affect supervision effectiveness. In the process of supervision, the government and the e-commerce enterprise constitute a dynamic and repeated game relationship, where two parties constantly correct their strategies through trial and error to maximize their own profits. Therefore, an evolutionary game model of government supervision and strategies of e-commerce enterprises is constructed to find effective equilibrium for government supervision.

In order to further discuss the effectiveness of government supervision, the degree of government supervision and enterprise profit are separated. For any e-commerce enterprise in the network market, it is assumed that the e-commerce enterprise has two strategies in the competitive market, namely, MO and IM. If e-commerce enterprise $i$ adopts MO, the profit is $\pi_{i}$; if e-commerce enterprise $i$ adopts IM, the profit can be increased by $\Delta \pi_{i}$; that is, the profit of adopting IM is $\pi_{i}+\Delta \pi_{i}$. For different choices, the government implements different degrees of supervision. The degree of supervision and supervision cost are generally corresponding; that is, the greater the degree, the greater the cost and the higher the probability of successful supervision. For the convenience of analysis, the supervision cost is used to reflect the degree of supervision, which does not affect the conclusions. Assume that when government supervision is successful, the supervision cost is $S_{g}$; when government supervision fails, the supervision cost is $S_{k}$. When government supervision is successful and all e-commerce enterprises adopt MO, the network market achieves the optimal operation, which will promote the development of the network economy, the increase of social welfare, and the enhancement of consumers' trust and support to the government. All these can be seen as the utility of government supervision. And suppose $f$ is the utility of government supervision, namely, the degree of consumers' support to the government. When the government supervision is successful, if an enterprise adopts IM, the enterprise will be punished, and the punishment is $F\left(F>\Delta \pi_{i}\right)$.

Based on Hofbauer et al. [39] and Shen and Wang [40], the profit matrix of government-supervised e-commerce enterprises is shown in Table 1.

In an evolutionary game model, the strategies of participants are mutually influenced. The growth rate of a certain strategy depends on the fitness, i.e., the strategy that produces higher profit has a higher growth rate. As a result, the government and the e-commerce enterprise can increase their profits by mimicking the strategies that succeed.

It is assumed that the e-commerce enterprise can randomly and independently choose MO or IM and repeat the game in the market. Assume that the probability of e-commerce enterprise 1 choosing $\mathrm{MO}$ is $p$, and the probability of choosing IM is $1-p$; the probability of successful government supervision is $q$, and the probability of supervision failure is $1-q$. According to the Malthusian equation [41], the growth rate $\dot{p} / p$ of e-commerce enterprise $i$ choosing MO should be equal to its fitness, $e_{1} A\{q, 1-q\}^{T}$, minus its average fitness, $\{p, 1-p\} A\{q, 1-q\}^{T} . e_{1}=[1,0]$ represents the e-commerce enterprise choosing $\mathrm{MO}$ with $100 \%$ probability. Then, the profit matrix of e-commerce enterprise $i$ is

$$
A=\left[\begin{array}{cc}
\pi_{i} & \pi_{i} \\
\pi_{i}+\Delta \pi_{i}-F & \pi_{i}+\Delta \pi_{i}
\end{array}\right] .
$$

So, $\dot{p}=p(1-p)\{1,-1\} A\{q, 1-q\}^{T}$, and it can be derived that $\dot{p}=p(1-p)\left(F q-\Delta \pi_{i}\right)$.

Similarly, considering the growth rate of government's supervision success, $\dot{q} / q$, it can be derived that $\dot{q}=q(1-q)\left[\left(F-S_{g}+S_{k}\right)+(f-F) p\right]$. The local stability of the system at equilibrium is analyzed using the Jacobian matrix [42]:

$$
J=\left[\begin{array}{ll}
\frac{\partial \dot{p}}{\partial p} & \frac{\partial \dot{p}}{\partial q} \\
\frac{\partial \dot{q}}{\partial p} & \frac{\partial \dot{q}}{\partial q}
\end{array}\right]=\left[\begin{array}{cc}
(1-2 p)\left(F q-\Delta \pi_{i}\right) & F p(1-p) \\
(f-F) q(1-q) & (1-2 q)\left[\left(F-S_{g}+S_{k}\right)+(f-F) p\right]
\end{array}\right]
$$

It can be derived that 
TABle 1: Profit matrix of government-supervised e-commerce enterprises.

\begin{tabular}{lccc}
\hline & & \multicolumn{2}{c}{ Government supervision } \\
& & Success & Failure \\
Strategies of e-commerce enterprises & MO & $\pi_{i}, f-S_{g}$ & $\pi_{i},-S_{k}$ \\
\hline
\end{tabular}

$$
\begin{aligned}
\operatorname{det} J & =(1-2 p)(1-2 q)\left(F q-\Delta \pi_{i}\right)\left[\left(F-S_{g}+S_{k}\right)+(f-F) p\right]-(f-F) F p q(1-q)(1-p), \\
\operatorname{tr} J & =(1-2 p)\left(F q-\Delta \pi_{i}\right)+(1-2 q)\left[\left(F-S_{g}+S_{k}\right)+(f-F) p\right] .
\end{aligned}
$$

The evolutionarily stable strategy (ESS) of the system is analyzed as follows:

(i) When $f<S_{g}-S_{k}$, according to $\dot{p}=0$ and $\dot{q}=0$, the system equilibrium is $(0,0),(0,1),(1,0),(1,1)$, and $\left(\left(F-\mathrm{S}_{\mathrm{g}}+\mathrm{S}_{\mathrm{k}}\right) /(F-f), \Delta \pi_{\mathrm{i}} / F\right)$.

(1) When $F>F-S_{g}+S_{k}>0, F>S_{g}-S_{k}>0$. The ESS analysis is shown in Table 2 .

(2) When $F-S_{g}+S_{k}<0,0<\Delta \pi_{i}<F<S_{g}-S_{k}$. The ESS analysis is shown in Table 3.

(ii) When $f>S_{g}-S_{k}$, according to $\dot{p}=0$ and $\dot{q}=0$, the system equilibrium is $(0,0),(0,1),(1,0)$, and $(1,1)$.

(1) When $F>F-S_{g}+S_{k}>0, F>S_{g}-S_{k}>0$. The ESS analysis is shown in Table 4 .

(2) When $F-\mathrm{S}_{\mathrm{g}}+\mathrm{S}_{\mathrm{k}}<0,0<\Delta \pi_{i}<F<\mathrm{S}_{\mathrm{g}}-\mathrm{S}_{\mathrm{k}}$. The ESS analysis is shown in Table 5.

From the analysis of Tables $2-5$, the ESS can be reached only when the consumer support for government regulation satisfies $f>S_{g}-S_{k}$, However, it is worth noting that when $0<\Delta \pi_{i}<F<S_{g}-S_{k}, \quad(0,0)$, i.e., government supervision fails and the e-commerce enterprise adopts IM, is also the ESS. Actually, this situation is the other extreme of the network market with EIBs of e-commerce enterprises, which is caused by the weaker government punishment $F<S_{g}-S_{k}$. Therefore, to ensure the normal operation of the network market, $(1,1)$ must be regarded as the only ESS of the evolutionary game, that is, the following conditions must be met:

$$
f>S_{g}-S_{k}, F>S_{g}-S_{k}>0, F>\Delta \pi_{i}, S_{g}>S_{k}>0 .
$$

(i) The government must punish enterprises that adopt IM. Only when the government's punishment is greater than the profit obtained by IM, i.e., $F>\Delta \pi_{i}$, enterprises will choose MO. Moreover, the higher the punishment imposed by the government, the greater the impact on the e-commerce enterprises and the fewer the enterprises adopting IM.

(ii) The degree of government supervision needs to be large, i.e., $S_{g}>S_{k}>0$. Only when the government supervision reaches a certain level, supervision can be effective. If government supervision is weak and of no practical significance, the supervision is just a thankless task. (iii) When the government supervision is enhanced, the increased supervision cost $S_{g}-S_{k}$ has to be compensated to maintain a high level of supervision. This requires the government to punish the enterprises that adopt IM at a punishment more than the increased cost, i.e., $F>S_{g}-S_{k}>0$.

(iv) The consumers' support that must be met, $f>S_{g}-S_{k}$, is an indispensable condition for successful government supervision. The timely and comprehensive feedback of consumers not only directly affect enterprises' reputation but also provide evidence for authorities of the government supervision, reducing the supervision cost and improving supervision efficiency.

\section{Practice and Discussion}

In the previous section, the conditions for the government to effectively supervise EIBs in the network market are obtained through an evolutionary game: the government punishes enterprises with immoral behaviors strongly enough, the degree of government supervision is high enough, the government needs to be compensated for the supervision cost, and consumers should support government supervision through feedback. Previous studies suggest that governments in developing countries should strengthen the regulation of online shopping markets compared to developed countries [35]. In most developing countries, e-commerce markets lack clear regulations and effective government oversight [34]. Moreover, counterfeit products damage more the reputation of developing countries than the economy. Therefore, it is more important for governments in developing countries to take strict measures to regulate online counterfeiting and other EIBs. Studies have shown that market self-regulation of counterfeit products in China is inefficient [43]. Based on this, the Chinese government's supervision on EIBs in the network market is used as a typical example in the section to verify the results obtained from the evolutionary game and to provide some managerial insights for countries where EIBs' regulation is inefficient or even ineffective.

From the practice in China, e-commerce platforms play an important role in combating immoral behaviors, and government supervision is indispensable. Besides, e-commerce platforms play the due role only when government supervision is effective. For example, Alibaba, a giant 
TABLE 2: The stability of the equilibrium in Case 1-(1).

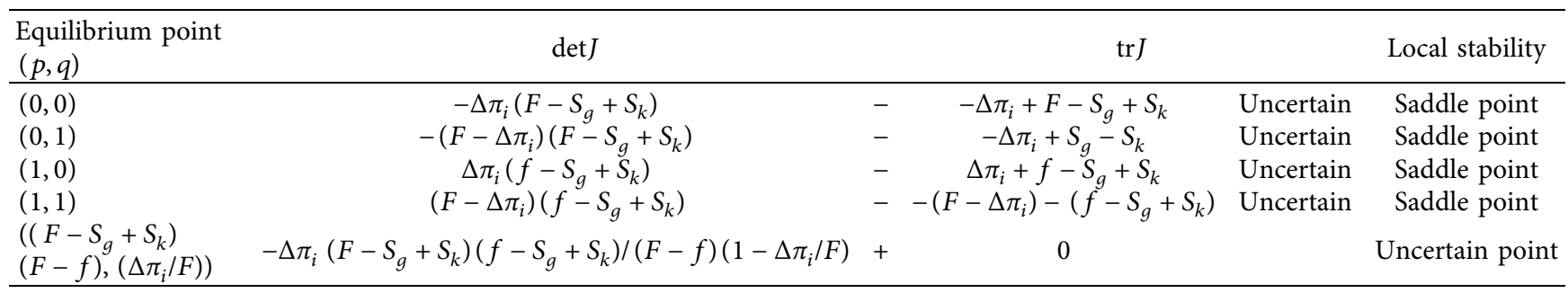

Table 3: The stability of the equilibrium in Case 1-(2).

\begin{tabular}{|c|c|c|c|c|c|}
\hline $\begin{array}{l}\text { Equilibrium point } \\
(p, q)\end{array}$ & $\operatorname{det} J$ & & $\operatorname{tr} J$ & & Local stability \\
\hline$(0,0)$ & $-\Delta \pi_{i}\left(F-S_{g}+S_{k}\right)$ & + & $-\Delta \pi_{i}+F-S_{g}+S_{k}$ & - & ESS \\
\hline$(0,1)$ & $-\left(F-\Delta \pi_{i}\right)\left(F-S_{g}+S_{k}\right)$ & + & $-\Delta \pi_{i}+S_{g}-S_{k}$ & + & Unstable point \\
\hline$(1,0)$ & $\Delta \pi_{i}\left(f-S_{g}+S_{k}\right)$ & & $\Delta \pi_{i}+f-S_{g}+S_{k}$ & Uncertain & Saddle point \\
\hline$(1,1)$ & $\left(F-\Delta \pi_{i}\right)\left(f-S_{g}+S_{k}\right)$ & - & $-\left(F-\Delta \pi_{i}\right)-\left(f-S_{g}+S_{k}\right)$ & Uncertain & Saddle point \\
\hline $\begin{array}{l}\left(\left(F-S_{g}+S_{k}\right)\right. \\
\left.(F-f),\left(\Delta \pi_{i} / F\right)\right)\end{array}$ & $-\Delta \pi_{i}\left(F-S_{g}+S_{k}\right)\left(f-S_{g}+S_{k}\right) /(F-f)\left(1-\Delta \pi_{i} / F\right)$ & + & 0 & & Uncertain point \\
\hline
\end{tabular}

TABLE 4: The stability of the equilibrium in Case 2-(1).

\begin{tabular}{|c|c|c|c|c|c|}
\hline Equilibrium point $(p, q)$ & $\operatorname{det} J$ & & $\operatorname{tr} J$ & & Local stability \\
\hline$(0,0)$ & $-\Delta \pi_{i}\left(F-S_{g}+S_{k}\right)$ & - & $-\Delta \pi_{i}+F-S_{g}+S_{k}$ & Uncertain & Saddle point \\
\hline$(0,1)$ & $-\left(F-\Delta \pi_{i}\right)\left(F-S_{g}+S_{k}\right)$ & - & $-\Delta \pi_{i}+S_{g}-S_{k}$ & Uncertain & Saddle point \\
\hline$(1,0)$ & $\Delta \pi_{i}\left(f-S_{g}+S_{k}\right)$ & + & $\Delta \pi_{i}+f-S_{g}+S_{k}$ & + & Unstable point \\
\hline$(1,1)$ & $\left(F-\Delta \pi_{i}\right)\left(f-S_{g}+S_{k}\right)$ & + & $-\left(F-\Delta \pi_{i}\right)-\left(f-S_{g}+S_{k}\right)$ & - & ESS \\
\hline
\end{tabular}

TABle 5: The stability of the equilibrium in Case 2-(2).

\begin{tabular}{|c|c|c|c|c|c|}
\hline Equilibrium point $(p, q)$ & $\operatorname{det} J$ & & $\operatorname{tr} J$ & & Local stability \\
\hline$(0,0)$ & $-\Delta \pi_{i}\left(F-S_{g}+S_{k}\right)$ & + & $-\Delta \pi_{i}+F-S_{g}+S_{k}$ & - & ESS \\
\hline$(0,1)$ & $-\left(F-\Delta \pi_{i}\right)\left(F-S_{g}+S_{k}\right)$ & + & $-\Delta \pi_{i}+S_{g}-S_{k}$ & + & Unstable point \\
\hline$(1,0)$ & $\Delta \pi_{i}\left(f-S_{g}+S_{k}\right)$ & + & $\Delta \pi_{i}+f-S_{g}+S_{k}$ & + & Unstable point \\
\hline$(1,1)$ & $\left(F-\Delta \pi_{i}\right)\left(f-S_{g}+S_{k}\right)$ & + & $-\left(F-\Delta \pi_{i}\right)-\left(f-S_{g}+S_{k}\right)$ & - & ESS \\
\hline
\end{tabular}

e-commerce enterprise in China, has a special antifaking office to deal with fakes in the network market after 2011, which is served by the deputy CFO as the administrator (the report is at https://tech.sina.com.cn/i/2016-07-01/docifxtsatm1135104.shtml). More than 2,000 employees are on full time to deal with counterfeits, another 5,000 social volunteers participate in antifaking, and the direct cost is about CNY 1 billion every year (the data can be retrieved from https://www.kaitao.cn/article/20170811102329.htm). Alibaba also conducts random inspections of goods through big data algorithms and initiates about 100,000 random inspections every year. CNY 100 million is invested to purchase goods sold on the platform. Once fakes are found, the goods will be removed, and the e-commerce enterprise will even be driven out of the platform (the report can be retrieved from http://paper.ce.cn/jjrb/html/2018-08/29/ content_371267.htm). Alibaba's antifaking measures were even appreciated by Doug Collins, the vice-chairman of the
US House Judiciary Committee (http://www.sofreight.com/ news_36233.html). Despite this, fakes on Taobao (http:// www.taobao.com), Tmall (http://www.tmall.com), and other websites are still difficult to eliminate, which is directly related to the lack of rigorous government supervision.

(i) The government's punishment for enterprises with immoral behaviors is too weak, leading to the existence of EIBs in the network market.

Different from traditional brick-and-mortar enterprises, e-commerce enterprises directly open stores in the network market, most of which are SMEs [44]. These e-commerce SMEs just need to meet the entry and selling rules and obtain the qualifications of the e-commerce platforms, while the offline enterprises must face the supervision of different authorities such as the Industry and Commerce Bureau and Tax Bureau and have to undertake 
multiple costs such as choosing site and decoration of brick-and-mortar stores. Some e-commerce SMEs even have only four or five employees to operate online stores. If e-commerce SMEs are investigated and forced to leave the platform due to immoral behaviors, they can change their names or move to another platform and then continue to sell products, and some of them even continue to adopt IM. On March 15, 2014, the State Administration for Industry and Commerce of China issued the Administrative Measures on Internet Transactions, which stipulates that online store owners will face fine of CNY 10,000 to CNY 30,000 (approximately USD 1450 to USD 4350) for providing false information about their products or services. With such a low punishment, it is difficult to curb the greed of counterfeiters. In response to this problem, during the Two Sessions (Two Sessions are the collective name for the National People's Congress of the People's Republic of China and the Chinese People's Political Consultative Conference held since 1959. Since the two conferences are basically coincident and the importance of the operation of the country is very high, it is referred to as Two Sessions. The significance of Two Sessions is to collect and organize the information and requirements of Two Sessions' representatives from the people and convey them to the central government.) of China in 2019, the head of China Market Supervisory Administration said that the government would impose huge punishments on fakes to greatly increase the cost of counterfeiters (the report is at https://news.sina.com.cn/o/2019-03-05/docihrfqzkc1428622.shtml).

Moreover, the illegality cost of e-commerce platforms selling fakes is also low, and platforms bear little joint liability; even some e-commerce enterprises are removed from the platform due to EIBs. In European countries, in the judicial decisions of similar cases, the e-commerce platforms are generally required to undertake joint liability. For example, it was reported that in 2008 , a court in Paris, France, ruled that eBay infringed on the rights of the LVHM Group and is enforced to compensate the company with $\$ 61$ million for selling fakes (the report is at http://news.winshang.com/html/044/ 2510.html). Besides, the e-commerce platforms are the most profitable enterprises, and even they sell fakes. Although some counterfeit information is transferred to the platform staff, they even cover up the immoral behaviors to ensure their own profits.

(ii) The low-degree government supervision on EIBs leads to inefficiency.

According to statistics, in 2016, Alibaba Platform Management Department used big data and manual reexamination methods to find out 4,495 enterprises that produce and sell fakes; their sales were far superior to the standard to be sentenced to jail
(CNY 50,000) (the report is at http://b2b.toocle. com/detail--6432092.html). Among them, the authorities accepted 1,184 cases and only can punish 469 cases under the current regulations. There were only 33 cases that can be confirmed as criminal judgments through public information, accounting for less than $1 \%$ of cases that can be punished. In the cases that have been sentenced, 37 of 47 were suspended, with a ratio of $79 \%$. Why the degree of government supervision of online shopping anticounterfeiting is so low? In addition to the hysteresis of the current law, this is also related to the performance evaluation of GDP growth and employment. All kinds of EIBs can meet the consumption needs of migrant workers and new residents in the process of urbanization. Moreover, the employment rate is increased by low-quality jobs due to the simplicity of producing and selling fakes. According to the data released by Zhiyan Consulting, the number of employees of Chinese WeChat shops exceeded 20 million in 2017 (the report is at http:// www.bbtnews.com.cn/2019/0531/304162.shtml). It is estimated that, by 2024 , the number will reach 52 million. The massive participation has prompted the development of e-commerce enterprises and also has caused many problems, such as tax evasion, sales of fakes, and disclosure of personal information. Many enterprises that produce and sell fakes are fully qualified and relatively large in scale, and some are even protected by the local governments. For example, in 2018, more than 100 enterprises producing condiments in a town in Tianjin, China, were closed. According to the survey, these enterprises were fraudulent for more than ten years, and the local government left them alone until they were exposed by the media (the report is at http://www. xinhuanet.com/fortune/2018-08/29/c_1123346277. htm).

(iii) The cost of government supervision cannot be compensated, leading to a loss of sustained motivation for supervision.

On April 14, 2016, the "QSIQ 12365 Complaint and Report Advisory Network" was launched in China. Through this website, consumers can check the information of enterprise product qualification and can also consult, complain, and report to the regional quality control departments. At the same time, to facilitate consumers to check the information of enterprise product qualification, Alibaba and other four e-commerce platforms were required to sign a cooperation agreement as a way to achieve the docking of e-commerce platforms and quality control website (the report is at https://www.sohu. com/a/69427874_350719). However, until today, e-commerce platforms have not realized the function of querying the product qualification, and the quality control website has not been effectively developed and used, which indicates that quality 
control in China has not achieved the expected results. On the one hand, this is due to the lack of clarity in the definition of responsibilities of government departments and the imperfect regulatory support system. On the other hand, the high cost and low return of government regulation also make the government have no incentive to regulate. Similarly, on January 1, 2019, the Chinese government introduced the E-Commerce Law, which explicitly brings EIBs such as data falsification into the scope of legal regulation. However, due to the high cost, government regulation is hardly effective as expected. In contrast, China's Antimonopoly Law was put in effect in 2008 and has been enforced for 12 years, with relevant administrative precedents amounting to CNY 12 billion. This makes the regulatory costs of government regulation compensable, thus making the regulation effective and sustainable. It is proved by the Chinese experience that government regulation can only be effective and sustainable if the costs of government supervision are compensated.

(iv) The lack of consumer rights and responsibilities contributes to the prevalence of counterfeit goods.

At present, customers hate fake foods and medicines but prefer low prices when purchasing other kinds of goods. In particular, consumers who are willing to buy fakes that involve intellectual property rights do not take it as a serious behavior. According to China's annual survey of Day for Consumers' Rights and Interests in 2019, less than $60 \%$ of consumers choose to protect their rights after buying fakes, and $16.11 \%$ of consumers continue to use fakes (the report is at https://www.thepaper.cn/newsDetail_forward_3141915). In the above survey, $33.59 \%$ of consumers believed that the low price is the main reason why counterfeit goods are difficult to ban.

In response to the increasingly serious e-commerce EIBs, the Chinese government has taken measures to increase the degree of government supervision and punishment to regulate the network market, which has already achieved preliminary success. Since October 2017, the National Development and Reform Commission has issued four blacklists for special management of untrustworthiness in the field of e-commerce, involving a total of 1092 enterprises (the report is at http://field.10jqka.com.cn/20181106/ c607973048.shtml). On May 14, 2018, the National Development and Reform Commission, the Central Network Information Office, the Ministry of Industry and Information Technology, etc., a total of 8 departments, jointly issued the Notice on Strengthening Special Governance Work on Untrustworthiness in the E-Commerce Sector to crack down illegal and untrustworthy behaviors in the field of e-commerce (the report is at http://www.sohu.com/a/ 273707363_100019209). In June 2018, the General Administration of China's Market Supervision, the National Development and Reform Commission, the Ministry of Industry and Information Technology, etc., a total of 11 departments, jointly issued the Notice on Printing and
Distributing the 2018 Network Market Supervision Special Action (Net Sword Action) Program, focusing on rectifying online infringement and false propaganda, false illegal advertising, etc. The Electronic Commerce Law of the People's Republic of China, which was officially implemented on January 1, 2019, regulates the rights and obligations of e-commerce enterprises and e-commerce platforms. In 2016, Alibaba provided a total of 4495 enterprises with EIBs whose sales exceeded CNY 50,000 to the national public security organizations. In 2017 and 2018, these data dropped to 1910 and 1634 (he reports are at http://www.cicn.com.cn/zggsb/ 2018-01/18/cms103803article.shtml and https:/baijiahao. baidu.com/s?id=1622256698847441370\&wfr=spider\&for= pc).

Among other countries, due to the lack of government supervision in the network market, Russia can only rely on several large-scaled platforms to spontaneously fight against fakes. Group-IB data showed that, in 2017, Russia's online counterfeit transactions exceeded USD 1.5 billion, a 23\% increase from 2016 (the blog can be retrieved from https:// blog.csdn.net/mozhe_/article/details/83105588). The US government has strengthened the government regulation on the network market. On April 3, 2019, President Trump signed a memorandum aiming at cracking down on online counterfeit transactions. It is recommended to enhance government supervision or legislative changes to better combat the sale of fakes. (the report is at https://www. stopfakes.gov/article?id=Presidential-Memorandum-onCombating-Trafficking-in-Counterfeit-and-Pirated-GoodsOpportunity-for-Stakeholder-Comments). Germany, whose network market operates in a good order, has imposed severe legal sanctions on the sale of fakes and ordered enterprises to return the fakes unconditionally within 14 days. Meanwhile, the blacklist of online shops selling fakes is established, and the public can expose online shops for selling fakes on the supervision website, making shops to be investigated and punished by the judicial agency.

\section{Conclusion and Policy Suggestion}

From the aforementioned model analysis and case discussion, it is found that, in many countries, especially in developing countries, inefficient government supervision is one of the critical factors for e-commerce enterprises adopting immoral behaviors. When e-commerce enterprises gain profits more through IM than through MO, EIBs appear. Only when government supervision and punishment are strict enough and punishment for the enterprise adopting IM is higher than the extra cost of government supervision, EIBs will be curbed. Besides, consumers' support is an essential factor in improving the efficiency of government supervision.

The governance of EIBs is a systematic project, and it is not enough to rely solely on government supervision. It is necessary to construct a new mechanism of social cogovernance of "enterprise initiative, industry self-regulation, social supervision, and government supervision." Note that the government's attitude and behavior about EIBs in the network market play an important role in guiding and 
guaranteeing the entire governance system. The following managerial implications can be summarized:

(i) There is an urgent need to improve the government supervision system for the network market. EIBs more easily occur in the online shopping market than in the traditional market. In the case of insufficient government supervision, the EIBs of e-commerce enterprises can cause great damage to the network market. Only by establishing a strict system of government supervision and making the punishment of IM higher than the increased profit by IM, the positive competition of the network market can be maintained.

(ii) Focus on supervising the EIBs of large enterprises. Large enterprises are the leader of the network market, whose probability of being found when adopting IM is much larger than that of SMEs. Government supervision on large enterprises can reduce the supervision cost and achieve effective supervision. Moreover, if large enterprises adopt MO and SMEs adopt IM, the living space of SMEs can be further compressed. However, there are a large number of SMEs in China, which make China's government supervision more difficult. This is also the subject of further research.

(iii) Encourage consumers to actively participate in the supervision of the network market. Consumers' support is of significance to reduce fakes, so protection laws and regulations for consumers should be improved to guide consumers to establish correct consumption concepts and consumption responsibilities. For example, India's newly revised Consumer Protection Act approved the establishment of the Central Consumer Protection Authority, which can authorize a centralized hotline for consumers to report any e-commerce fraudulent transaction. At present, less than $50 \%$ of countries have established online consumer protection laws.

(iv) Accelerate the establishment of the enterprise credit system, which can limit the behaviors of immoral enterprises. Establish a credit evaluation system for e-commerce platforms with department linkage, data sharing, and enterprise participation. Moreover, third-party organizations are encouraged to publish professional credit ratings for e-commerce enterprises and e-commerce platforms.

This paper finds that consumer participation in the regulation of network markets is crucial. In addition to this, the government should encourage the public, media, nongovernmental organizations, and other stakeholders to participate in EIB regulation. However, how to establish an effective hybrid governance system combining government supervision and informal regulation has not been explored in this paper, and this is the direction of our future research.

\section{Data Availability}

The data used to support the findings of this study are included within the article.

\section{Conflicts of Interest}

The authors declare that there are no conflicts of interest regarding the publication of this article.

\section{Acknowledgments}

This paper was supported by the National Natural Science Foundation of China (no. 71971129), Shandong Province Higher Education Youth Innovation and Technology Support Program (no. 2019RWG017), and Shandong Provincial Natural Science Foundation (ZR201911160259). The authors would like to thank Dr. Rongyun Tang of the University of Tennessee for providing grammatical and syntactic corrections to the paper.

\section{References}

[1] W.-y. Kevin Chiang and G. E. Monahan, "Managing inventories in a two-echelon dual-channel supply chain," European Journal of Operational Research, vol. 162, no. 2, pp. 325-341, 2005.

[2] Z. Zhang, S. Liu, and B. Niu, "Coordination mechanism of dual-channel closed-loop supply chains considering product quality and return," Journal of Cleaner Production, vol. 248, Article ID 119273, 2020.

[3] D. Palmer, "Extending the process model of collective corruption," Research in Organizational Behavior, vol. 28, pp. 107-135, 2008.

[4] Y. Komarova Loureiro, K. L. Haws, and W. O. Bearden, "Businesses beware," Journal of Service Research, vol. 21, no. 2, pp. 184-200, 2018.

[5] Y. Komarova Loureiro, J. Bayuk, S. M. Tignor, G. Y. Nenkov, S. Baskentli, and D. Webb, "The case for moral consumption: examining and expanding the domain of moral behavior to promote individual and collective well-being," Journal of Public Policy \& Marketing, vol. 35, no. 2, pp. 305-322, 2016.

[6] J. R. McColl-Kennedy, B. A. Sparks, and D. T. Nguyen, "Customer's angry voice: targeting employees or the organization?” Journal of Business Research, vol. 64, no. 7, pp. 707-713, 2011.

[7] M. Safaei and K. D. Thoben, "Measuring and evaluating of the network type impact on time uncertainty in the supply networks with three nodes," Measurement, vol. 56, pp. 121127, 2014.

[8] P. A. Pavlou, H. Liang, and Y. Xue, "Understanding and mitigating uncertainty in online exchange relationships: a principal-agent perspective," MIS Quarterly, vol. 31, no. 1, pp. 105-136, 2007.

[9] M. Rothschild and J. Stiglitz, "Equilibrium in competitive insurance markets: an essay on the economics of imperfect information," The Quarterly Journal of Economics, vol. 90, no. 4, pp. 629-649, 1976.

[10] D. Peterson, "Perceived leader integrity and ethical intentions of subordinates," Leadership \& Organization Development Journal, vol. 25, no. 1, pp. 7-23, 2004.

[11] G. Labianca, J. F. Fairbank, G. Andrevski, and M. Parzen, "Striving toward the future: aspiration-performance 
discrepancies and planned organizational change," Strategic Organization, vol. 7, no. 4, pp. 433-466, 2009.

[12] F. Gino, J. Gu, and C.-B. Zhong, "Contagion or restitution? When bad apples can motivate ethical behavior," Journal of Experimental Social Psychology, vol. 45, no. 6, pp. 1299-1302, 2009.

[13] S. Otim and V. Grover, "E-commerce: a brand name's curse," Electronic Markets, vol. 20, no. 2, pp. 147-160, 2010.

[14] P.-L. To, C. Liao, and T.-H. Lin, "Shopping motivations on Internet: a study based on utilitarian and hedonic value," Technovation, vol. 27, no. 12, pp. 774-787, 2007.

[15] Y. Wang, J. Yang, and L. Qi, "A game-theoretic model for the role of reputation feedback systems in peer-to-peer commerce," International Journal of Production Economics, vol. 191, pp. 178-193, 2017.

[16] C. Oliver, "Strategic responses to institutional processes," Academy of Management Review, vol. 16, no. 1, pp. 145-179, 1991.

[17] J. J. Kish-Gephart, D. A. Harrison, and L. K. Treviño, "Bad apples, bad cases, and bad barrels: meta-analytic evidence about sources of unethical decisions at work," Journal of Applied Psychology, vol. 95, no. 1, pp. 1-31, 2010.

[18] L. K. Treviño, G. R. Weaver, and S. J. Reynolds, "Behavioral ethics in organizations: a review," Journal of Management, vol. 32, no. 6, pp. 951-990, 2006.

[19] M. Faccio, "Politically connected firms," American Economic Review, vol. 96, no. 1, pp. 369-386, 2006.

[20] J.-J. Laffont and D. Martimort, "The design of transnational public good mechanisms for developing countries," Journal of Public Economics, vol. 89, no. 2-3, pp. 159-196, 2005.

[21] T. Mavlanova, R. Benbunan-Fich, and G. Lang, "The role of external and internal signals in E-commerce," Decision Support Systems, vol. 87, pp. 59-68, 2016.

[22] D. D. Bergh, B. L. Connelly, D. J. Ketchen, and L. M. Shannon, "Signalling theory and equilibrium in strategic management research: an assessment and a research agenda," Journal of Management Studies, vol. 51, no. 8, pp. 1334-1360, 2014.

[23] S. Román and P. J. Cuestas, "The perceptions of consumers regarding online retailers' ethics and their relationship with consumers' general internet expertise and word of mouth: a preliminary analysis," Journal of Business Ethics, vol. 83, no. 4, pp. 641-656, 2008.

[24] D. Walsh, J. M. Parisi, and K. Passerini, "Privacy as a right or as a commodity in the online world: the limits of regulatory reform and self-regulation," Electronic Commerce Research, vol. 17, no. 2, pp. 185-203, 2017.

[25] C. Mutimukwe, E. Kolkowska, and Å. Grönlund, "Information privacy in e-service: effect of organizational privacy assurances on individual privacy concerns, perceptions, trust and self-disclosure behavior," Government Information Quarterly, vol. 37, no. 1, Article ID 101413, 2020.

[26] I.-D. Anic, V. Škare, and I. Kursan Milaković, "The determinants and effects of online privacy concerns in the context of e-commerce," Electronic Commerce Research and Applications, vol. 36, Article ID 100868, 2019.

[27] C.-H. Wu, Z. Yan, S.-B. Tsai, W. Wang, B. Cao, and X. Li, “An empirical study on sales performance effect and pricing strategy for E-commerce: from the perspective of mobile information," Mobile Information Systems, vol. 2020, Article ID 7561807, 8 pages, 2020.

[28] M. M. Calkins, A. Nikitkov, and V. Richardson, "Mineshafts on treasure island: a relief map of the eBay fraud landscape," Pittsburgh Journal of Technology Law and Policy, vol. 8, 2008.
[29] A. G. González, "PayPal and eBay: the legal implications of the C2C electronic commerce model," in Proceedings of the The 18th BILETA Conference: Controlling Information in the Online Environment, London, UK, April 2003.

[30] E. L. Glaeser and A. Shleifer, "A reason for quantity regulation," American Economic Review, vol. 91, no. 2, pp. 431-435, 2001.

[31] J. E. Oxley and B. Yeung, "E-commerce readiness: institutional environment and international competitiveness," Journal of International Business Studies, vol. 32, no. 4, pp. 705-723, 2001.

[32] M. G. Martinsons, "Electronic commerce in China: emerging success stories," Information \& Management, vol. 39, no. 7, pp. 571-579, 2002.

[33] L. E. Ribstein and B. H. Kobayashi, "State regulation of electronic commerce," SSRN Electronic Journal, vol. 51, no. 1, pp. 1-31, 2002.

[34] R. AlGhamdi and S. Drew, "Seven key drivers to online retailing in KSA," in Proceedings of the IADIS International Conference on e-Society, Avila, Spain, 2012.

[35] A. Agrawal, C. Catalini, and A. Goldfarb, "Some simple economics of crowdfunding," Innovation Policy and the Economy, vol. 14, no. 1, pp. 63-97, 2014.

[36] H. Kim, "Globalization and regulatory change: the interplay of laws and technologies in E-commerce in Southeast Asia," Computer Law \& Security Review, vol. 35, no. 5, Article ID 105315, 2019.

[37] P. Weiser, "The future of internet regulation," University of California Davis Law Review, vol. 43, pp. 529-590, 2009.

[38] C. T. Marsden, "Beyond Europe: the Internet, regulation, and multistakeholder governance-Representing the consumer interest?" Journal of Consumer Policy, vol. 31, no. 1, pp. 115-132, 2008.

[39] J. Hofbauer, P. Schuster, and K. Sigmund, "A note on evolutionary stable strategies and game dynamics," Journal of Theoretical Biology, vol. 81, no. 3, pp. 609-612, 1979.

[40] L. Shen and Y. Wang, "Supervision mechanism for pollution behavior of Chinese enterprises based on haze governance," Journal of Cleaner Production, vol. 197, pp. 571-582, 2018.

[41] J. W. Weibull, Evolutionary Game Theory, Princeton Press, Princeton, NJ, USA, 1995.

[42] D. Friedman, "Evolutionary games in economics," Econometrica, vol. 59, no. 3, pp. 637-666, 1991.

[43] E. J. Balleisen, "Extracts from government and markets: toward a new theory of regulation," in The Prospects for Effective Coregulation in the United States: A Historian's View for the Early Twenty-First Century, E. J. Balleisen and A. David, Eds., pp. 450-453, Cambridge University Press, New York, NY, USA, 2010.

[44] R. Ramanathan, U. Ramanathan, and H.-L. Hsiao, "The impact of e-commerce on taiwanese SMEs: marketing and operations effects," International Journal of Production Economics, vol. 140, no. 2, pp. 934-943, 2012.

[45] D. J. Brass, K. D. Butterfield, and B. C. Skaggs, "Relationships and unethical behavior: a social network perspective," Academy of Management Review, vol. 23, no. 1, pp. 14-31, 1998.

[46] C. Chen, J. Zhang, and T. Delaurentis, "Quality control in food supply chain management: an analytical model and case study of the adulterated milk incident in China," International Journal of Production Economics, vol. 152, pp. 188-199, 2014.

[47] D. Rodrigues, R. Teixeira, and J. Shockley, "Inspection agency monitoring of food safety in an emerging economy: a multilevel analysis of Brazil's beef production industry," International Journal of Production Economics, vol. 214, pp. 1-16, 2019. 